\title{
cDNA Cloning and Functional Analyses of Ashitaba (Angelica keiskei) Sesquiterpene Synthase Genes
}

\author{
Kurin limura ${ }^{1}$, Jun-ichiro Hattan ${ }^{2}$, Norihiko Misawa ${ }^{2}$, and Kazutoshi Shindo ${ }^{1 *}$ \\ ${ }^{1}$ Department of Food and Nutrition, Japan Women's University, 2-8-1 Mejirodai, Bunkyo-ku, Tokyo, 112-8681, JAPAN \\ ${ }^{2}$ Research Institute for Bioresources and Biotechnology, Ishikawa Prefectural University, 1-308 Suematsu, Nonoichi-shi, Ishikawa, 921-8836, \\ JAPAN
}

\begin{abstract}
Angelica keiskei (ashitaba) is an edible plant belonging to the Apiacea family. We focused on sesquiterpenes in the leaves eaten by humans (specifically, in the Japanese population), and confirmed the presence of several sesquiterpenes by GC-MS. Thus, total RNA was extracted from the ashitaba leaves, reverse transcribed, and the resultant cDNAs were used for degenerate PCR followed by rapid amplification of cDNA ends. Consequently, we were able to isolate two full-length $T p s$ genes (designated $A k T p s 1$ and AkTps2). Functional analysis of these two genes was carried out with Escherichia coli cells that expressed mevalonate pathway genes to increase the substrate (farnesyl diphosphate) amount of sesquiterpene synthase, revealing that $A k T p s 1$ encodes germacrene $D$ synthase, and $A k T p s 2$ codes for an enzyme that catalyzes the generation of germacrene $B$ and smaller amounts of germacrene $D$ (a germacrene $B$ and $D$ synthase). We proposed biosynthetic routes of these two sesquiterpenes from farnesyl diphosphate (FPP) via farnesyl cation.
\end{abstract}

Key words: sesquiterpene, terpene synthase, ashitaba

\section{Introduction}

Sesquiterpenes, which are major components of floral scents, are C15 members of the terpenoid family that are composed of three isoprene (C5) units. More than 7000 sesquiterpenes have been identified from higher plants and other organisms ${ }^{1,2)}$. It is well known that sesquiterpenes possess various pharmaceutical functions, as well as flavoring effects, e.g., artemisin from Artemisia annua has antimalarial activity ${ }^{3)}$, zerumbone from Zingiber zerumbet has antitumor activity ${ }^{4)}$, and nerolidol, farnesol, bisabolol, and apritone enhance bacterial permeability and susceptibility to exogenous antimicrobial compounds ${ }^{5}$. These findings suggest that sesquiterpenes are important compounds for human life and health.

Angelica keiskei (ashitaba) is an edible plant belonging family Apiacea, which is native to the Pacific coast of Japan $^{6)}$. Humans ingest the boiled, baked, or fried leaves and stems of ashitaba, which possess a bitter taste and specific flavor. In addition, the extract of this plant has been reported to exhibit anti-inflammatory, antiobesity, antioxidative, anticoagulant, antitumor, antimutagenic, antidiabetic, antibacterial, and hepato-protective activities ${ }^{7)}$. In addition, several bioactive compounds have been isolated from ashitaba, e.g., chalcones in the roots, which function as antibacterial, antidiabetic, and antiplatelet compounds ${ }^{6,8)}$, and ashitabaol $\mathrm{A}$ in the seeds, which functions as an antioxidant $^{9)}$. However, except for ashitabaol A, no studies have reported the formation of sesquiterpenes in ashitaba. On the other hand, other Apiacea family plants have been reported to produce many sesquiterpenes, including epikuzeaol, $\delta$-cadinene, $(E)$ - $\beta$-caryophyllene, $\alpha$-humulene, germacrene $\mathrm{D}$, farnesene, guaiol, and bulnesol ${ }^{10-13)}$.

Sesquiterpenes are synthesized from farnesyl diphosphate (FPP) by terpene synthases (TPSs). Harada and Misawa (2009) created a similar process in Escherichia coli, establishing an efficient system for synthesis of sesquiterpenes using acetoacetate as the main substrate ${ }^{14)}$. Using this system, the functions of TPSs from various species have been analyzed and many sesquiterpenes have been synthesized artificially ${ }^{15)}$. Thus, we hypothesized that this system would be useful for studying ashitaba TPSs. In this study, we used gas chromatography-mass spectrometry (GC-MS) to analyze sesquiterpenes in ashitaba leaves, identified TPS genes from these leaves, and analyzed their enzymatic functions. This is the first study to report sesquiterpenes and TPSs in the edible ashitaba plant.

\footnotetext{
*Correspondence to: Kazutoshi Shindo, Department of Food and Nutrition, Japan Women's University, 2-8-1 Mejirodai, Bunkyo-ku, Tokyo, 112-8681, JAPAN

E-mail: kshindo@fc.jwu.ac.jp

Accepted March 3, 2020 (received for review October 30, 2019)

Journal of Oleo Science ISSN 1345-8957 print / ISSN 1347-3352 online

http://www.jstage.jst.go.jp/browse/jos/ http://mc.manusriptcentral.com/jjocs
} 


\section{K. Iimura, J. Hattan, N. Misawa et al.}

\section{Materials and Methods}

\subsection{Plant}

Ashitaba was purchased from a commercial dealer (Ouchi Saien, Kanagawa, Japan). The leaves were sampled and immediately frozen in liquid nitrogen. The tissues were stored at $-80^{\circ} \mathrm{C}$ until use.

\subsection{GC-MS analyses of ashitaba extract}

Five grams of ashitaba leaves were ground into powder in liquid nitrogen and the volatile constituents were extracted with $3 \mathrm{~mL}$ methanol. After adding $1.5 \mathrm{~mL} n$-hexane, the mixture was shaken by vortex and the upper phase was collected for GC-MS analysis. GC-MS analysis was performed as described by Hattan et al. ${ }^{16)}$.

A Shimadzu GCMS-QP2010 (Shimadzu, Kyoto, Japan) equipped with a DB-5ms capillary column (0.25-mm internal diameter $\times 0.25 \mu \mathrm{m} \times 30 \mathrm{~m}$, Agilent Technologies) was used for analysis. Split injections $(1 \mu \mathrm{L})$ were made at a ratio of 10:1 with an injection room temperature of $260^{\circ} \mathrm{C}$. The heating program of the column oven was heating to $40^{\circ} \mathrm{C}$ (held for $1 \mathrm{~min}$ ), increasing at $4^{\circ} \mathrm{C} / \mathrm{min}$ up to $120^{\circ} \mathrm{C}$, then increasing by $15^{\circ} \mathrm{C} / \mathrm{min}$ up to $260^{\circ} \mathrm{C}$ (held for $4 \mathrm{~min}$ ). Mass spectra were monitored in the mass range of $\mathrm{m} / \mathrm{z}$ 45-250 with an electron voltage at $1.15 \mathrm{kV}$ and an interface temperature at $280^{\circ} \mathrm{C}$.

\subsection{RNA extraction and cDNA synthesis}

Frozen leaves were ground and total RNA was extracted using the RNeasy Plant Mini Kit(Qiagen, Madison, USA). After the concentration of total RNA was determined using a Nano Drop 2000 (Thermo Fisher Scientfic, Tokyo, Japan), first strand cDNA was synthesized from $1.0 \mu \mathrm{g}$ of total RNA using the SMARTer RACE cDNA amplification kit(Takara Bio, Shiga, Japan).

\section{4 cDNA cloning of AkTps1}

In order to amplify Tps gene fragments, PCR was performed using Taq DNA polymerase ( + dNTPs) Robust buffer (Bioacademia, Osaka, Japan)with two degenerate primers $\left(5^{\prime}-\mathrm{TT}(\mathrm{C} / \mathrm{T}) \mathrm{CGA}(\mathrm{C} / \mathrm{T}) \mathrm{TI}(\mathrm{C} / \mathrm{T}) \mathrm{TI}(\mathrm{A} / \mathrm{C}) \mathrm{G}(\mathrm{A} / \mathrm{G})(\mathrm{A} /\right.$ C) A (A/G) CAIGG-3' and 5'-TAIG (A/C/T) (A/G) TCA (A/T) $\left.\mathrm{AI}(\mathrm{A} / \mathrm{G}) \mathrm{T}(\mathrm{A} / \mathrm{G}) \mathrm{TC}(\mathrm{A} / \mathrm{G}) \mathrm{TC}-3^{\prime}\right)$, which were successfully used for cloning Tps gene fragments from Zingiber zerumbet Smith $^{17)}$. The PCR condition were as follows: $94^{\circ} \mathrm{C}$ for $3 \mathrm{~min}, 5$ cycles of three steps $\left(94^{\circ} \mathrm{C}\right.$ for $30 \mathrm{~s}, 35^{\circ} \mathrm{C}$ for $60 \mathrm{~s}$ and $72^{\circ} \mathrm{C}$ for $60 \mathrm{~s}$ ) and 30 cycles of three steps $\left(94^{\circ} \mathrm{C}\right.$ for $30 \mathrm{~s}, 40^{\circ} \mathrm{C}$ for $60 \mathrm{~s}$ and $72^{\circ} \mathrm{C}$ for $\left.60 \mathrm{~s}\right)$. Unless otherwise stated, PCR mixture contained $1 \mu \mathrm{L}$ cDNA template, $5 \mu \mathrm{M}$ of each primer, $125 \mu \mathrm{M}$ each of dNTP and $1 \mathrm{U}$ of Tag DNA polymerase in $20 \mu \mathrm{L}$.

Using PCR product as a template, nested PCR was performed with two primers (5'-TTGCTAGCGTGGTGGAA-3' and 5'-TAIG (A/C/T) (A/G) TCA (A/T) AI (A/G) T (A/G) TC (A/ G) TC-3'). The PCR condition were as follows: $94^{\circ} \mathrm{C}$ for 3 min and 30 cycles of three steps $\left(94^{\circ} \mathrm{C}\right.$ for $30 \mathrm{~s}, 40^{\circ} \mathrm{C}$ for 60 $\mathrm{s}$, and $72^{\circ} \mathrm{C}$ for $60 \mathrm{~s}$ ).

The PCR products were ligated into pGEM-T Easy vector (Promega) and transformed into XL-1 Blue. Sequences of PCR products were analyzed using BigDye Terminator version 3.1 (Applied Biosystems, CA, USA) and ABI3130xl genetic analyzer (Applied Biosystems). Unless otherwise stated, sequences of PCR products were analyzed in the same manner.

To amplify the Tps 3' region, primers were designed form the cDNA fragment cloned in above and 3' RACE was performed. PCR was performed with 5'-GGTGTACTTTGAGCCACGTT-3' and 5'-AACTGGAAGAATTCGCGGCC-3', and the PCR conditions were as follows: $94^{\circ} \mathrm{C}$ for $3 \mathrm{~min}, 30$ cycles of three steps $\left(94^{\circ} \mathrm{C}\right.$ for $30 \mathrm{~s}, 58^{\circ} \mathrm{C}$ for $30 \mathrm{~s}$, and $72^{\circ} \mathrm{C}$ for $70 \mathrm{~s}$ ). Using the PCR product as a template, nested PCR was performed with primers ( $5^{\prime}$-CAGCCCGAATATTTCTTACCAAAG-3' and 5'-TCGCGGCCGCAGGAA-3'). The PCR conditions were as follows: $94^{\circ} \mathrm{C}$ for 3 min, 35 cycles of three steps $\left(94^{\circ} \mathrm{C}\right.$ for $30 \mathrm{~s}, 58^{\circ} \mathrm{C}$ for $30 \mathrm{~s}$, and $72^{\circ} \mathrm{C}$ for $70 \mathrm{~s}$ ).

BLASTX searching showed that the cloned cDNA fragment was similar to germacrene D synthase of Thapsia villosa var. laciniate (KR822706). Thus, for getting the longer fragments of ashitaba Tps, the forward primer (5'ATCATCCTAGCATCTGGGGAGAC-3') was designed from the germacrene D synthase gene of Thapsia villosa var. laciniate and the reverse primer 5'-GTACACCCCCGTTATCCAAAAGTAGC-3' was designed from cDNA fragment cloned above, respectively. PCR with these primers was performed under the following conditions: $94^{\circ} \mathrm{C}$ for $3 \mathrm{~min}$, 35 cycles of three steps $\left(94^{\circ} \mathrm{C}\right.$ for $30 \mathrm{~s}, 60^{\circ} \mathrm{C}$ for $30 \mathrm{~s}$, and $72^{\circ} \mathrm{C}$ for $45 \mathrm{~s}$ ).

To amplify a Tps 5' end of the ashitaba Tps gene, primers were designed from the cDNA fragment cloned above and 5' RACE was performed. First, PCR was performed with UPM (mixture of 5'-CTAATACGACTCACTATAGGGCAAGCAGTGGTATCAACGCAGAGT-3' and 5'CTAATACGACTCACTATAGGGC-3') and another primer 5'GCCGCCGTCTGATGGCTTTCCGGTCT-3' under the following conditions: $94^{\circ} \mathrm{C}$ for $3 \mathrm{~min}, 25$ cycles of three steps $\left(94^{\circ} \mathrm{C}\right.$ for $30 \mathrm{~s}, 68^{\circ} \mathrm{C}$ for $30 \mathrm{~s}$, and $72^{\circ} \mathrm{C}$ for $\left.180 \mathrm{~s}\right)$. Then, using PCR product as a template, nested PCR was performed with 5'-CTAATACGACTCACTATAGGGC-3' and 5'-CAGCTTCAAAGTGGTACGACAACCCCAGCC-3' under the same condition as above.

\section{5 cDNA cloning of AkTps2}

In order to amplify another Tps fragments, PCR was performed using Taq DNA polymerase ( + dNTPs) Robust buffer (Bioacademia) with two degenerate primers (5'-GAT$\operatorname{GTTGC}(\mathrm{A} / \mathrm{T} / \mathrm{C}) \mathrm{CT}(\mathrm{A} / \mathrm{T})(\mathrm{A} / \mathrm{T} / \mathrm{C}) \mathrm{G}(\mathrm{C} / \mathrm{T}) \mathrm{TT}(\mathrm{C} / \mathrm{T})(\mathrm{A} / \mathrm{C})$ G-3' and 5'-TC (C/T) T (A/C/G) ATT (A/T/C) AT (A/G) TC (C/ T) TTCCA-3'), which were designed using relatively well- 
conserved regions in Apiaceae Tps sequences. The PCR condition were as follows: $94^{\circ} \mathrm{C}$ for $3 \mathrm{~min}, 35$ cycles of three steps $\left(94^{\circ} \mathrm{C}\right.$ for $30 \mathrm{~s}, 40^{\circ} \mathrm{C}$ for $30 \mathrm{~s}$, and $72^{\circ} \mathrm{C}$ for $\left.50 \mathrm{~s}\right)$.

To amplify the 3 ' region, primers were designed form the cDNA fragment cloned above and 3' RACE was performed. PCR was performed with 5'-TACTACCTCTCACCTTCATCTCT-3' and 5'-AACTGGAAGAATTCGCGGCC-3', and the PCR conditions were as follows: $94^{\circ} \mathrm{C}$ for 3 min, 30 cycles of three steps $\left(94^{\circ} \mathrm{C}\right.$ for $30 \mathrm{~s}, 58^{\circ} \mathrm{C}$ for $30 \mathrm{~s}$, and $72^{\circ} \mathrm{C}$ for $50 \mathrm{~s}$ ). Using PCR product as a template, nested PCR was performed with primers (5'-GGGGCTTTACTTTGAGCCCCAA-3' and 5'-TCGCGGCCGCAGGAA$\left.3^{\prime}\right)$. The PCR conditions were as follows: $94^{\circ} \mathrm{C}$ for $3 \mathrm{~min}, 35$ cycles of three steps $\left(94^{\circ} \mathrm{C}\right.$ for $30 \mathrm{~s}, 58^{\circ} \mathrm{C}$ for $30 \mathrm{~s}$, and $72^{\circ} \mathrm{C}$ for $60 \mathrm{~s}$ ).

To amplify the 5' end of ashitaba Tps, primers were designed from the cDNA fragment cloned above and 5' RACE was performed. First, PCR was performed with UPM ( mixture of $5^{\prime}$ - C T A A T A C G A C T C A C TATAGGGCAAGCAGTGGTATCAACGCAGAGT-3' and 5'CTAATACGACTCACTATAGGGC-3') and 5'-CCATGAAACACTCAACGGCTGACGGTATA-3' under the following conditions: $94^{\circ} \mathrm{C}$ for $3 \mathrm{~min}, 25$ cycles of three steps $\left(94^{\circ} \mathrm{C}\right.$ for $30 \mathrm{~s}, 68^{\circ} \mathrm{C}$ for $30 \mathrm{~s}$, and $72^{\circ} \mathrm{C}$ for $180 \mathrm{~s}$ ). Then, using PCR product as a template, nested PCR was performed with 5'-CTAATACGACTCACTATAGGGC-3' and 5'-ATAATCGAAGCCGTGTGTCGGCCCTGCTTC-3' under the same conditions as above.

The generated PCR products were analyzed as described just before in the Materials and methods section of cDNA cloning of AkTps1.

\subsection{Phylogenetic analysis}

BLASTX searches were carried out against the GeneBank non-redundant protein database on NCBI. Alignment of multiple protein sequences was carried out using BioEdit or EMBOSS Needle, and the phylogenic tree was drawn using Mega-X.

\subsection{Functional analysis of $A k T p s 1$}

PCR was performed using KOD-Plus-Neo (Toyobo, Fukui, Japan) with primers 5'-GGGCATATGGCTCTGTTTGTGCTCTC-3' and 5'-CCCCTCGAGCTACCATGATACTGGAATAGGATC-3'. These primers contained NdeI and XhoI restriction endonuclease recognition sites, respectively. PCR mixture contained $1 \mu \mathrm{L}$ cDNA template, $0.3 \mu \mathrm{M}$ of each primer, $400 \mu \mathrm{M}$ each of dNTP and $1 \mathrm{U}$ of KOD-PlusNeo in $50 \mu \mathrm{L}$. PCR conditions were as follows: $94^{\circ} \mathrm{C} 2 \mathrm{~min}$, 25 cycles of three steps $\left(98^{\circ} \mathrm{C} 10 \mathrm{~s}, 55^{\circ} \mathrm{C} 30 \mathrm{~s}\right.$, and $68^{\circ} \mathrm{C} 60$ s). After these cycles, $5 \mathrm{U}$ of Taq DNA polymerase was added to the mixture, and reacted for $600 \mathrm{~s}$ at $72^{\circ} \mathrm{C}$. The PCR products were cloned into pGEM-T Easy vector and their sequences were analyzed. The entire Tps open reading frame $(\mathrm{ORF})$ from ashitaba was separated from the plasmid by NdeI and XhoI digestion and inserted into the NdeI-XhoI site of pETDuet-1 (Merck, Darmstadt, Germany) to construct the plasmid named pET-AkTps1. The obtained plasmid was introduced into $E$. coli BL21 (DE3) together with plasmid pAC-Mev/Scidi/Aacl ${ }^{14}$.

Recombinant $E$. coli were culture in LB medium containing $50 \mu \mathrm{g} / \mathrm{mL}$ ampicillin (Am) and $30 \mu \mathrm{g} / \mathrm{mL}$ chloramphenicol $(\mathrm{Cm})$ at $37^{\circ} \mathrm{C}$ overnight. One milliliter of this culture was inoculated into $100 \mathrm{~mL}$ of TB medium in a 500-mL Erlenmeyer flask containing $50 \mu \mathrm{g} / \mathrm{mL} \mathrm{Am}, 30 \mu \mathrm{g} /$ $\mathrm{ml} \mathrm{Cm}$, and $1 \mathrm{mg} / \mathrm{mL}$ lithium acetoacetate (LAA) and cultured at $37^{\circ} \mathrm{C}$ with rotary shaking (150 rpm) for 3-4 h. After cooling the flask to $20^{\circ} \mathrm{C}, 25 \mu \mathrm{M}$ isopropyl $\beta$-Dthiogalactopyranoside(IPTG) and $20 \mathrm{~mL} n$-octane were added to the flask and cultured at $20^{\circ} \mathrm{C}$ with rotary shaking for 2 days.

The contents of 12 flasks were added to $n$-hexane ( 400 $\mathrm{mL}$ ) and poured into a separatory funnel and shaken well. The alkane layer $(n$-octane $+n$-hexane $)$ was washed with an equal amount of alkaline $90 \% \mathrm{MeOH}(0.5 \mathrm{M} \mathrm{KOH}$ in $90 \% \mathrm{MeOH})$ twice and concentrated to a small volume (3 $\mathrm{mL}$ ) in vacuo. The concentrated alkane was applied on a silica gel(Silica Gel 60, Kanto Chemical) chromatography column (20 i.d. $\times 200 \mathrm{~mm}$ ) filled with $n$-pentane, and developed with $n$-pentane.

The eluates were fractionated every $5 \mathrm{~g}$, and the sesquiterpenes included in each fraction were analyzed by silica gel TLC developed with $n$-hexane. By spraying molybdophophoric acid solution (12 g disodium molybdate(VI) dihydrate, $1.5 \mathrm{~mL} \mathrm{H}_{3} \mathrm{PO}_{4}, 25 \mathrm{~mL} \mathrm{H}_{2} \mathrm{SO}_{4}$ in $500 \mathrm{~mL}$ distilled water) on the developed TLC plate and heating to $200^{\circ} \mathrm{C}$, the produced sesquiterpenes were detected as blue spots (Rf value 0.7).

The fractions containing a sesquiterpene (fr. 8-10, 9.8 $\mathrm{mg}$ ) were concentrated to dryness in vacuo and analyzed by ${ }^{1} \mathrm{H}$ NMR (Bruker, AMX400) using TMS as an internal $\operatorname{standard}(\delta 0.00)$ and GC-MS.

\subsection{Functional analysis of $A k T p s 2$}

PCR was performed using KOD-Plus-Neo with primers 5'-CGCAGAGTACATGGGGTGATAA-3' and 5'-GCAAGTGGCAAACACCAACTCA-3'. PCR condition was as follows: $94^{\circ} \mathrm{C} 2 \mathrm{~min}, 25$ cycles of three steps $\left(98^{\circ} \mathrm{C} 10 \mathrm{~s}, 55^{\circ} \mathrm{C} 30 \mathrm{~s}\right.$, $\left.68^{\circ} \mathrm{C} 60 \mathrm{~s}\right)$. PCR mixture contained $1 \mu \mathrm{L}$ cDNA template, $0.3 \mu \mathrm{M}$ of each primer, $400 \mu \mathrm{M}$ each of dNTP and $1 \mathrm{U}$ of KOD-Plus-Neo in $50 \mu \mathrm{L}$. With PCR product as a template, nested PCR was performed with 5'-CATATGGCGGCTCTTGTTCA-3' and 5'-AGATCTTTACACTGGAATAGGATCAATT-3' under the same condition above. These primers contained NdeI and BglII restriction endonuclease recognition sites, respectively. After these cycles, $5 \mathrm{U}$ of Taq DNA polymerase was added to the mixture, and reacted for 600 $\mathrm{s}$ at $72^{\circ} \mathrm{C}$. The PCR products were cloned into pGEM-T Easy vector and their sequences were analyzed. 


\section{K. Iimura, J. Hattan, N. Misawa et al.}

The entire Tps ORF from ashitaba was separated from the plasmid by NdeI and BglII digestion and inserted into the NdeI-BglII site of the pRSFDuet-1 (Merck) and constructed the plasmid was named pRSFD-AkTps2. The obtained plasmid was introduced into E. coli BL21 (DE3) together with plasmid pAC-Mev/Scidi/Aacl ${ }^{14}$.

Isolation of the produced sesquiterpenes was performed according to the method described in the Materials and methods section of functional analysis of AkTps1. The silica column fractions that contained one sesquiterpene (Rf 0.7) (fr. 8-11, 1.8 mg) or other one (Rf 0.5) (fr. 23-31, $2.5 \mathrm{mg}$ ) were collected separately, and analyzed by ${ }^{1} \mathrm{H}$ NMR and GC-MS.

\section{9 ${ }^{1} \mathrm{H}$ NMR analyses of the produced sesquiterpenes}

Each isolated sesquiterpene was analyzed by ${ }^{1} \mathrm{H}$ NMR (Bruker, AMX400). ${ }^{1} \mathrm{H}$ NMR spectra were measured in $\mathrm{CDCl}_{3}$ using the residual solvent peak as an internal standard $\left(\delta_{\mathrm{H}} 7.26 \mathrm{ppm}\right)$.

Germacrene D $\delta: 0.80(\mathrm{~d} J=6.8 \mathrm{~Hz}, 3 \mathrm{H}, \mathrm{H}-13), 0.86(\mathrm{~d} J$ $=6.8 \mathrm{~Hz}, 3 \mathrm{H}, \mathrm{H}-14), 1.40-1.52(2 \mathrm{H}, \mathrm{H}-8 \mathrm{~b}$, and H-8a), 1.42 (m, 1H, H-12), 1.52 (s, 3H, H-15), 1.95 (m, 1H, H-2b), 2.02 (m, 1H, H-7) , 2.08 ( $\mathrm{m}, 1 \mathrm{H}, \mathrm{H}-3 \mathrm{~b}), 2.10-2.30$ (2H, H-9b, and $\mathrm{H}-9 \mathrm{a}), 2.40$ (2H, H-2a, and H-3a), 4.74(s, 1H, H-11b), 4.79 (s, 1H, H-11a), $5.13(\mathrm{~m}, 1 \mathrm{H}, \mathrm{H}-1), 5.25$ (dd $J=10.0,15.8$

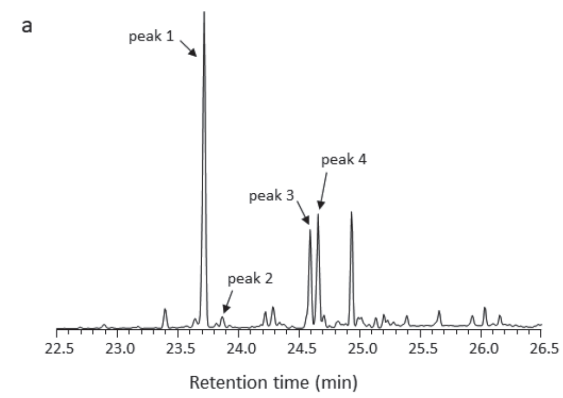

b

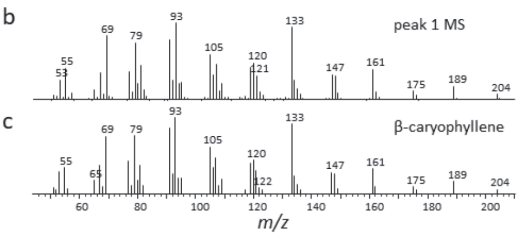

j<smiles>C=C1CCC=C2CCC3C(C)(C)CC123</smiles><smiles>CCC1=C(C)CC(C)=CCCC(C)=CC1</smiles>

$\beta$-caryophyllene

germacrene B
$\mathrm{Hz}, 1 \mathrm{H}, \mathrm{H}-6), 5.80$ (d $J=15.8 \mathrm{~Hz}, 1 \mathrm{H}, \mathrm{H}-5)$.

Germacrene B $\delta: 1.50(\mathrm{~s}, 3 \mathrm{H}, \mathrm{H}-15), 1.54(\mathrm{~s}, 3 \mathrm{H}, \mathrm{H}-11)$, 1.69 (s, 3H, H-13), 1.71 (s, 3H, H-14), 1.80 (m, 1H, H-8b), $1.95(\mathrm{~m}, 1 \mathrm{H}, \mathrm{H}-3 \mathrm{~b}), 2.04-2.07(2 \mathrm{H}, \mathrm{H}-9 \mathrm{~b}$ and $\mathrm{H}-2 \mathrm{~b}), 2.17$ (m, 1H, H-3a), 2.21 (m, 1H, H-9a), 2.29 (m, 1H, H-2a), 2.52 - $2.58(2 \mathrm{H}, \mathrm{H}-8 \mathrm{a}$ and $\mathrm{H}-6 \mathrm{~b}), 2.92$ (m, 1H, H-6a), 4.50 (m, $1 \mathrm{H}, \mathrm{H}-5), 4.72(\mathrm{~m}, 1 \mathrm{H}, \mathrm{H}-1)$.

\section{Results}

\subsection{GC-MS analysis of ashitaba leaf extract}

GC-MS analysis of the ashitaba leaf extract detected several sesquiterpenes, including $\beta$-caryophyllene, $\beta$-himachalene, germacrene $\mathrm{D}$, and germacrene $\mathrm{B}$, which were deduced from the MS database (Fig. 1).

\section{2 cDNA cloning of ashitaba Tps1 and ashitaba Tps2}

Two full-length Tps genes, designated AkTps1 and AkTps2, were isolated (accession No. LC506578 and LC506579, respectively). The deduced amino acid sequences of AkTPS1 and AkTPS2 consisted of 569 and 567 amino acids, respectively. BLAST searching showed that AkTPS1 has $81 \%$ identity to germacrene D synthase of Trachyspermum ammi (AUZ98407) and AkTPS2 has 72\%
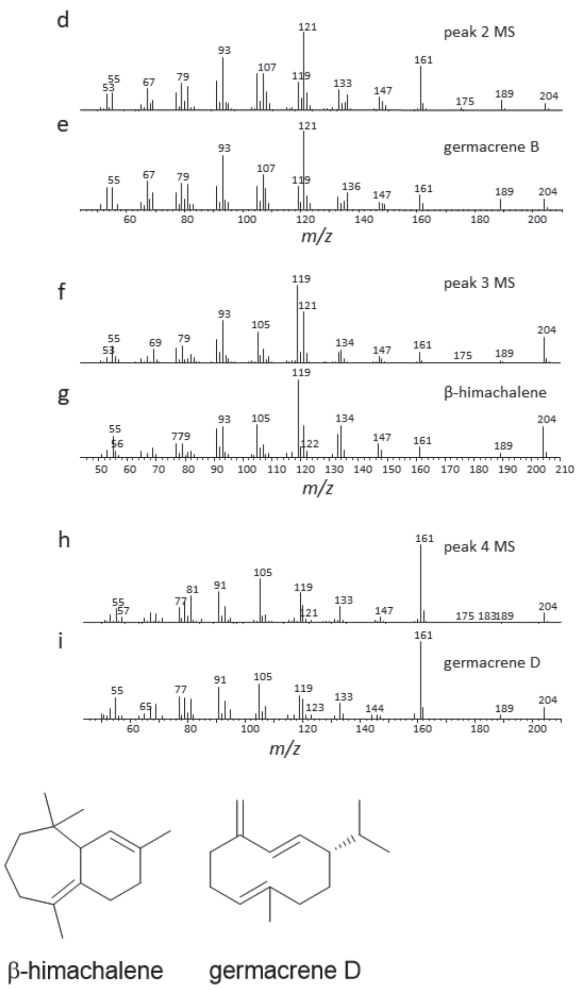

Fig. 1 Gas chromatography-mass spectrometry (GC-MS) analysis of the volatile compounds in ashitaba leaf extract.

TIC of the extract(a), MS of peak 1(b), MS of $\beta$-caryophyllene in the database(c), MS of peak 2(d), MS of germacrene B in the database (e), MS of peak $3(\mathrm{f})$, MS of $\beta$-Himachalene in the database (g), MS of peak $4(\mathrm{~h})$, MS of germacrene $\mathrm{D}$ in the database $(\mathrm{i})$, and structures of each sesquiterpene $(\mathrm{j})$. 
identity to germacrene D synthase of Thapsia villosa var. laciniatta (AMU19318). The similarity between AkTPS1 and AkTPS2 was 84.8\%. In general, TPSs have aspartate rich motifs, such as the RDR, DDxxD, and NSE/DTE motifs $^{16)}$. These motifs were all conserved in AkTPS1 and AkTPS2 (Fig. 2). Phylogenetic analyses revealed that AkTPS1 and AkTPS2 are more similar to germacrene D synthases of species belonging to the Apiaceae family than ones of other families (Fig. 3).

\subsection{Functional analyses of AkTPS1 and AkTPS2} 3.3.1 AkTPS1

Silica gel column fractions 8-10, which contained a sesquiterpene, were concentrated to dryness $(9.8 \mathrm{mg})$ and analyzed by ${ }^{1} \mathrm{H}$ NMR. The sesquiterpene was identified as germacrene D by comparison the observed ${ }^{1} \mathrm{H}$ NMR spectrum (Fig. S-1) with the previously reported ${ }^{1} \mathrm{H}$ NMR data ${ }^{15)}$. GC-MS analysis using the conditions described in material and method section also proved the sesquiterpene as germacrene $\mathrm{D}$ (retention time $24.6 \mathrm{~min}$, MS data match rate
$98 \%)$.

3.3.2 AkTPS2

The silica gel column fractions 8-12 and 23-28, containing different sesquiterpenes, were concentrated to dryness (1.8 $\mathrm{mg}$ and $2.5 \mathrm{mg}$, respectively) and analyzed by ${ }^{1} \mathrm{H}$ NMR. These sesquiterpenes were identified as germacrene D (fractions 8-12) and germacrene $\mathrm{B}$ (fraction 23-28), respectively, by comparison the observed ${ }^{1} \mathrm{H}$ NMR spectra (germacrene D (Fig. S-1) and germacrene B (Fig. S-2)) with the previously reported ${ }^{1} \mathrm{H}$ NMR data ${ }^{15,18)}$. GC-MS analysis using the conditions described in material and method section also proved them as germacrene $\mathrm{D}$ (retention time $24.6 \mathrm{~min}$, MS data match rate $98 \%$ ) and germacrene $\mathrm{B}$ (retention time $23.8 \mathrm{~min}$, MS data match rate $99 \%)$

\section{Discussion}

Angelica keiskei(ashitaba) is an edible plant belonging

\begin{abstract}
AkTPS1 1 MAL FVLSTSS S PPNV- VPE I TRKKS APYHPS I WGNKFLADSDS SVVKTDL 49 AkTPS2 1 MAALVHST SGPPPKVAMPE I AR-KS AS YHPS I WGDRFLAYSNPAVLKTDV 49

AkTPS1 50 DHEEEEHHQLLKQEVKKML I AGDR SQEL I SL I DD I QRLGLS YHF EAE I D 99 AkTPS2 50 DHKEEVHLQLLKEEVKKMLVAKDK TQDEL I SL I DD I QRLGL S YHF EAE L 99

AkTPS1 100 TLLQd I QRCHEYYGS KTDDDLHDVALCFRLLRQQGHNVS SDVFYKFKDS 149 AkTPS2 100 TLLQHIKDS F REYYGS KTDHDLRDVALCFRLLRQQGHF IS SDVFYKFKDN 149

AkTPS1 150 DGKFKENLVKDVKG I LSLF EAAHLRVHGEDVLDDALEFTT SHLKQHMNSN 199 AkTPS2 150 KGKFKENMVKDVRGMLSLLEATHLRVNGDD ILEEALEFTT SHLHL YKNSN 199

AkTPS1 200 L S S PLGDLVARALKYPLRKS L NRL VARHY I S I YHKFHRHNQVLLNLAKCD 249 AkTPS2 200 MNDPLVELVDRELRCPLRMGVNRLVARHY I S I YHKFDWHNQVLLDLAKCD 249

AkTPS1 250 FNLVQKLHQKELGH I TRWWKDLDF ANKL P F ARDRVVECY FW I TGVYFEPR 299 AkTPS2 250 FNRVQKVHQMEL AH I TRWWKDLDF ANKL PF ARDR I VECYFW I L GL Y FEPQ 299

AkTPS1 300 YATAR I FLTKV I SLT SVVDD I YDVR GT I EEARQFTDA I EKWD I SS IDELP 349 AkTPS2 300 YAKAR I FLTQVI S LT S IVDDTYDVYGT AEE L QQF TDA I QKWD I S I LDQLP 349

AkTPS1 350 EYMRQCYQPLLDVF AEAKAE I AKTGKPSDGG I GYALNAYKRL TRAYLQEA 399 AkTPS2 350 EYMRF PYQVLLDVF AKAEEDMVKEAGPTH - GF DYAKDAFKRLTRSYHQES 398

AkTPS1 400 EWCQVNYF PTFEEYMSVALVTGAFKLLSVSS FVLMGDVATRESFDWMS KD 449 AkTPS2 399 KWCQVSY F PTFEEYMS VACVS DGMKMLS I T S FVLMGNVATKEAFEWMS KD 448

AkTPS1 450 PL IVRASS I CRL TDDMVGHEFEQQRPHVPS A IECFMKQYGVQEDTAIDA 499 AkTPS2 449 PL I LRAMSVI GRLKND I VGHENERKRPH I PS AVECFMEQYDVPKE I AYDA 498

AkTPS1 500 LQKR I KNAWKDMNQECLHPMAAPMPML TRVFNL ACV I NLLYD-GYDGYTH 548 AkTPS2 499 LKKHI TNAWKD INQECLHP I A I PAPL I EKVFNF SCVTNL I YDEGF DAYT I 548

AkTPS1 549 S STRTKDMI TS ILLDP I PVSW

AkTPS2 549 S SSRTKEKI T SLLIDP I PV- -

569 567
\end{abstract}

Fig. 2 Sequence alignment of AkTPS1 and AkTPS2.

Amino acid sequences deduced from Tps genes isolated from ashitaba were aligned. The TPS conserved motifs RDR, DDxxD, and NSE/DTE are indicated by gray lines. Amino acids conserved between AkTPS1 and AkTPS2 are indicated in black boxes. 


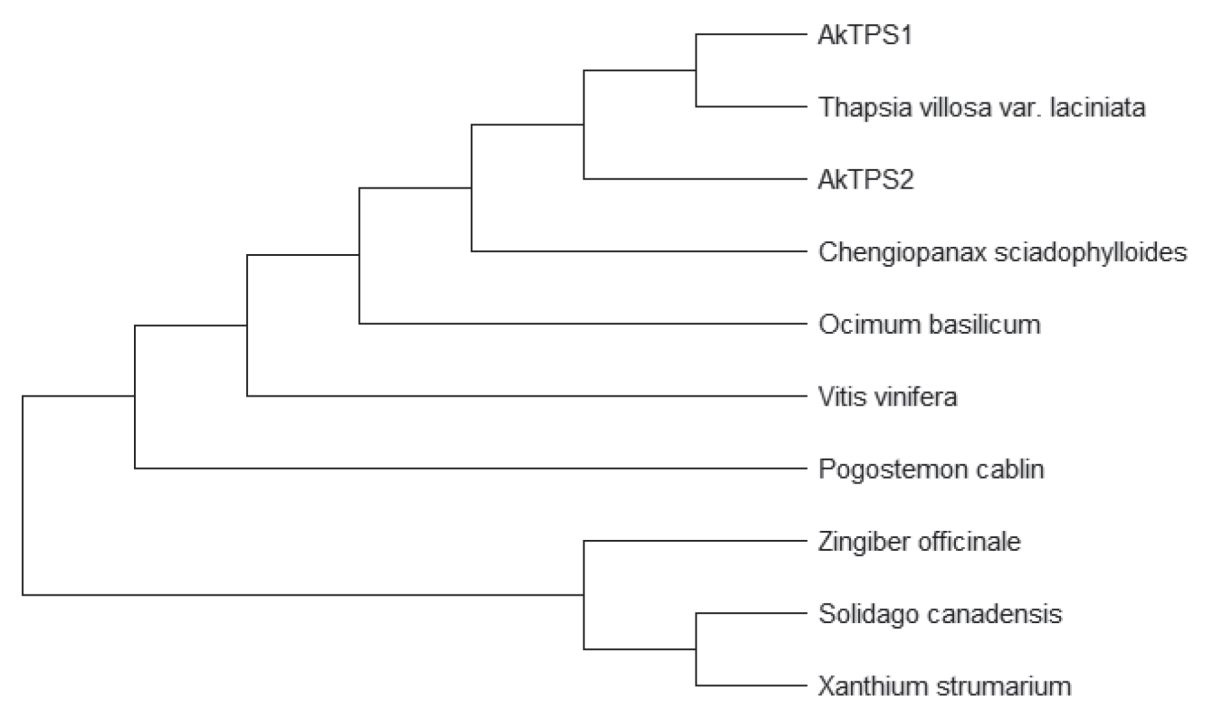

Fig. 3 Phylogenetic tree of AkTPS1, AkTPS2, and known germacrene D synthases.

AkTPS1, AkTPS2, and known germacrene D synthases were phylogenetically analyzed. Accession numbers are as follows: Chengiopanax sciadophylloides germacrene D synthase(BBE32331), Ocimum basilicum germacrene D synthase (AAV63786), Pogostemon cablin germacrene D synthase (AAS86320), Solidago canadensis germacrene D synthase (CAE47440), Thapsia villosa var. laciniata germacrene D synthase (AMU19318), Vitis vinifera germacrene D synthase(AAS66357), Xanthium strumarium germacrene D synthase (AMP42987), and Zingiber officinale germacrene D synthase (AAX40665).

to the Apiacea family. In the present study, we focused on sesquiterpenes present in the leaves eaten by humans (specifically, in the Japanese population), from which only one sesquiterpene has been reported previously. GC-MS analysis of the leaf extract resulted in the detection of $\beta$-caryophyllene, $\beta$-himachalene, germacrene $\mathrm{D}$, and germacrene B. We identified two sesquiterpene synthase genes (designated AkTps1 and AkTps2), which were germacrene D synthase and germacrenes B and D synthase, respectively.

Phylogenetic analyses revealed that AkTPS1 and AkTPS2 were more similar to germacrene D synthases from species belonging to the same Apiaceae family than ones from other families (Fig. 3). For example, similarity between AkTPSs and germacrene D synthase from Thapsia villosa var. laciniata (AMU19318) of the same family was over $80 \%$, while only approximately $50 \%$ similarity was observed between AkTPSs and germacrene D synthase from Zingiber officinale (DAY860846). AkTPSs also showed over $80 \%$ similarity to kuzeaol synthase of Thapsia garganica (K4LMW2). Structural diversity of germacrene D synthase enzymes is likely to be the result of convergent evolution. Thus, it is difficult to estimate function of each unknown TPS sequences by sequence-based dry analysis. Therefore, functional analysis experiments of individual TPSs should be needed, e.g., by using a mevalonate-pathway-engineered E. coli.

As germacrene $\mathrm{D}$ is reported to have antioxidant and antibacterial activities ${ }^{19,20)}$, this compound may contribute to the relevant activities of ashitaba leaves. In addition, sesquiterpenes, including germacrene $\mathrm{D}$, are known to be emitted in response to biotic environmental stress ${ }^{21,22)}$. As insect pests have become problematic in the culture of ashitaba $^{23)}$, sesquiterpenes should be a focus of research directed toward this problem.

Many TPSs contribute to multi-sesquiterpene synthesis ${ }^{13,24,25)}$, and these multi-sesquiterpene synthases contribute to the diversity of sesquiterpenes in plants ${ }^{26)}$. AkTPS2 found in this study also belongs to this multi-sesquiterpene synthase due to the production of two sesquiterpenes, germacrene $\mathrm{D}$ and germacrene $\mathrm{B}$. Tps genes encoding enzymes that catalyze the formation of germacrene D and germacrene B, like AkTPS2, have been identified in Valeriana officina$l i s^{24)}$. Here, we propose biosynthetic routes from FPP to these two sesquiterpenes by way of a farnesyl cation, as shown in Fig. 4. Cation A(Fig. 4), generated from farnesyl cation, is likely to be a starting point for germacrene $\mathrm{D}$ and germacrene $\mathrm{B}$ synthesis. Considering the products of AkTPS1 (germacrene D) and AkTPS2 (germacrene B and germacrene $\mathrm{D}$ ), the selective dehydrogenation of $\mathrm{H}-7$ from cation A in AkTPS1 may be caused by a strict steric interaction between the binding pocket of AkTPS1 and the substrate.

In this study, we were not able to identify Tps genes for $\beta$-caryophyllene synthase or $\beta$-himachalene synthase, although these sesquiterpenes were detected by GC-MS. Nine sesquiterpenes were detected in the case of carrot (Daucus carota), a plant belonging to family Apiacea, and 


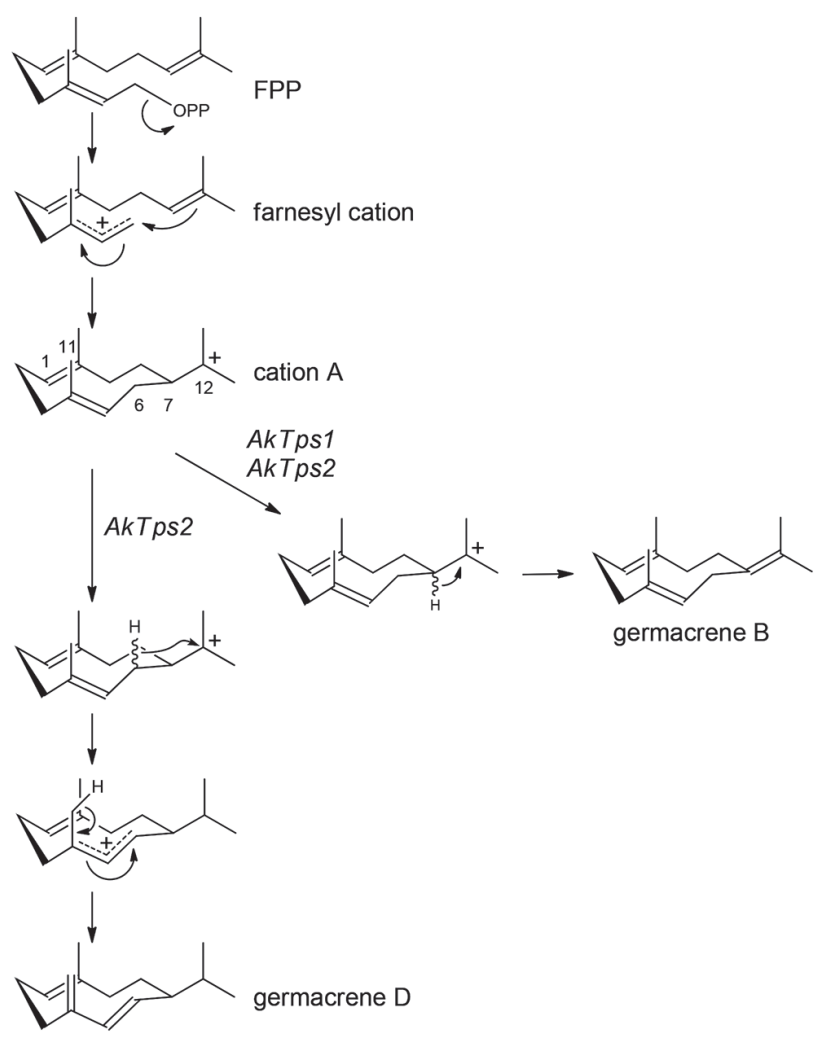

Fig. 4 Proposed biosynthetic routes of germacrene B and germacrene D.

22 sesquiterpene synthases were suggested to exist in that species $^{27)}$. It is thus likely that many unidentified sesquiterpene synthases exist in ashitaba, which can contribute to its diverse biological functions.

\section{Conclusions}

In the present study, we confirmed the presence of several sesquiterpenes in Angelica keiskei (ashitaba) for the first time. We cloned two Tps genes from the edible leaves and expressed them in MVA-pathway-engineered $E$. coli. Products of the TPSs were analyzed by ${ }^{1} \mathrm{H}$ NMR and GC-MS. Consequently, a germacrene D synthase gene, named AkTps1, and a germacrenes B and D synthase gene, named AkTps2, were identified. This is the first study reporting TPSs of the ashitaba plant.

\section{Acknowledgments}

We thank Ms. Moe Usui, Ms. Mayuko Sugita, Ms. Yurie Sugiyama, Ms. Mei Ogawa, Ms. Yuka Hashimoto, and Ms. Sonmi Li for their experiments. This work was supported in part by the commission for Development of Artificial Gene Synthesis Technology for Creating Innovative Bioma- terial from the Ministry of Economy, Trade and Industry, Japan.

\section{Supporting Information}

This material is available free of charge via the Internet at http://dx.doi.org/jos.69.10.5650/jos.ess 19275

\section{References}

1) Bohlmann, J.; Meyer-Gauen, G.; Croteau, R. Plant terpenoid synthases: Molecular biology and phylogenetic analysis. Proc. Natl. Acad. Sci. USA 95, 4126-4133 (1998).

2) Duhl, T.R.; Helmig, D.; Guenther, A. Sesquiterpene emissions from vegetation: a review. Biogeosciences 5, 761-777 (2008).

3) Enserink, M. Infectious diseases. Source of new hope against malaria is in short supply. Science 307, 33 (2005).

4) Murakami, A.; Takahashi, D.; Kinoshita, T.; Koshimizu, K.; Kim, H.W.; Yoshihiro, A.; Nakamura, Y.; Jiwajinda, S.; Terao, J.; Ohigashi, H. Zerumbone, a Southeast Asian ginger sesquiterpene, markedly suppresses free radical generation, proinflammatory protein production, and cancer cell proliferation accompanied by apoptosis: the $\alpha, \beta$-unsaturated carbonyl group is a prerequisite. Carcinogenesis 23, 795-802(2002).

5) Brehm-Stecher, B.F.; Johnson, E.A. Sensitization of Staphylococcus aureus and Escherichia coli to antibiotics by the sesquiterpenoids nerolidol, farnesol, bisabolol, and apritone. Antimicrob. Agents. Chemother. 47, 3357-3360 (2003).

6) Caesar, L.K.; Cech, N.B. A review of the medicinal uses and pharmacology of ashitaba. Planta Med. 82, 1236-1245(2016).

7) Kil, Y.S.; Pham, S.T.; Seo, E.K.; Jafari, M. Angelica keiskei, an emerging medicinal herb with various bioactive constituents and biological activities. Arch. Pharm. Res. 40, 655-675(2017).

8) Ohkura, N.; Ohnisi, K.; Taniguchi, M.; Nakayama, A.; Usuba, Y.; Fujita, M.; Fujii, A.; Ishibashi, K.; Baba, K.; Atsumi, G. Anti-platelet effects of chalcones from Angelica keiskei Koidzumi (Ashitaba) in vivo. Pharmazie 71, 651-654(2016).

9) Aoki, N.; Ohta, S. Ashitabaol A, a new antioxidative sesquiterpenoid from seeds of Angelica keiskei. Tetrahedron Lett. 51, 3449-3450 (2010).

10) Pickel, B.; Drew, D.P.; Manczak, T.; Weitzel, C.; Simonsen, H.T.; Ro, D.K. Identification and characterization of a kunzeaol synthase from Thapsia garganica: Implications for the biosynthesis of the pharmaceutical 


\section{K. Iimura, J. Hattan, N. Misawa et al.}

thapsigargin. Biochem. J. 448, 261-271(2012).

11) Andersen, T.; Cozzi, F.; Simonsen, H. Optimization of biochemical screening methods for volatile and unstable sesquiterpenoids using HS-SPME-GC-MS. Chromatography 2, 277-292(2015).

12) Yahyaa, M.; Tholl, D.; Cormier, G.; Jensen, R.; Simon, P.W.; Ibdah, M. Identification and characterization of terpene synthases potentially involved in the formation of volatile terpenes in carrot (Daucus carota L.) roots. J. Agric. Food Chem. 63, 4870-4878(2015).

13) Andersen, T.B.; Rasmussen, S.A.; Christensen, S.B.; Simonsen, H.T. Biosynthesis of tovarol and other sesquiterpenoids in Thapsia laciniata Rouy. Phytochemistry 157, 168-174(2019).

14) Harada, H.; Misawa, N. Novel approaches and achievements in biosynthesis of functional isoprenoids in Escherichia coli. Appl. Microbiol. Biotechnol. 84, 1021-1031 (2009).

15) Shindo, K.; Hattan, J.I.; Kato, M.; Sato, M.; Ito, T.; Shibuya, Y.; Watanabe, A.; Sugiyama, M.; Nakamura, Y.; Misawa, N. Purification and structural analysis of volatile sesquiterpenes produced by Escherichia coli carrying unidentified terpene synthase genes from edible plants of the family Araliaceae. Biosci. Biotechnol. Biochem. 82, 978-985(2018).

16) Hattan, J.; Shindo, K.; Sasak, T.; Misawa, N. Isolation and functional characterization of new terpene synthase genes from traditional edible plants. J. Oleo Sci. 67, 1235-1246 (2018).

17) Yu, H.; Harada, H.; Yamasaki, K.; Okamoto, S.; Hirase, S.; Tanaka, Y.; Misawa, N.; Utsumi, R. Isolation and functional characterization of a $\beta$-eudesmol synthase, a new sesquiterpene synthase from Zingiber zerumbet Smith. FEBS Lett. 582, 565-572(2008).

18) Adio, A.M.; Paul, C.; Kloth, P.; König, W.A. Sesquiterpenes of the liverwort Scapania undulata. Phytochemistry 65, 199-206 (2004).

19) Rather, M.A.; Dar, B.A.; Dar, M.Y.; Wani, B.A.; Shah, W.A.; Bhat, B.A.; Ganai, B.A.; Bhat K.A.; Anand, R.; Qurishi, M.A.; Anand, R.; Qurishi, M.A. Chemical composition, antioxidant and antibacterial activities of the leaf essential oil of Juglans regia L. and its constituents. Phytomedicine 19, 1185-1190(2012).
20) Shindo, K. A modern purification method for volatile sesquiterpenes produced by recombinant Escherichia coli carrying terpene synthase genes. Biosci. Biotechnol. Biochem. 82, 935-939(2018).

21) Arimura, G.; Huber, D.P.; Bohlmann, J. Forest tent caterpillars (Malacosoma disstria) induce local and systemic diurnal emissions of terpenoid volatiles in hybrid poplar(Populus trichocarpa x deltoides): cDNA cloning, functional characterization, and patterns of gene expression of (-)-germacrene D synthase, PtdTPS1. Plant J. 34, 603-616(2004).

22) Tholl, D. Terpene synthases and the regulation, diversity and biological roles of terpene metabolism. Curr. Opin. Plant Biol. 9, 297-304(2006).

23) Takeuchi, K.; Takeuchi, J. Occurrence of insect pests in ashitaba (Angelica keiskei) field in Tokyo and biological notes on Sitochroa palealis (Lepidoptera: Crambidae). Annual Report of the Kanto-Tosan Plant Protection Society 56, 95-97(2009). (in Japanese).

24) Pyle, B.W.; Tran, H.T.; Pickel, B.; Haslam, T.M.; Gao, Z.; MacNevin, G.; Vederas, J.S.; Kim, S.U.; Ro, D.K. Enzymatic synthesis of valerena-4, 7 (11)-diene by a unique sesquiterpene synthase from the valerian plant (Valeriana officinalis). FEBS J. 279, 3136-3146(2012).

25) Hattan, J.; Shindo, K.; Sasaki, T.; Ohno, F.; Tokuda, H.; Ishikawa, K.; Misawa, N. Identification of novel sesquiterpene synthase genes that mediate the biosynthesis of valerianol, which was an unknown ingredient of tea. Sci. Rep. 8, 12474(2018).

26) Köllner, T.G.; Schnee, C.; Gershenzon, J.; Degenhardt, $J$. The variability of sesquiterpenes emitted from two Zea mays cultivars is controlled by allelic variation of two terpene synthase genes encoding stereoselective multiple product enzymes. Plant Cell 16, 1115-1131 (2004).

27) Keilwagen, J.; Lehnert, H.; Berner, T.; Budahn, H.; Nothnagel, T.; Ulrich, D.; Dunemann, F. The terpene synthase gene family of carrot (Daucus carota L.): Identification of QTLs and candidate genes associated with terpenoid volatile compounds. Front. Plant Sci. 8, 1930 (2017). 